\title{
Optimisation of Cost in Ground Improvement for Upcoming Navi Mumbai International Airport
}

\author{
M. P. Suryawanshi, Raju Narwade, Karthik Nagrajan
}

\begin{abstract}
This study aimed to optimise the cost of ground improvement by considering the residual settlement in marshy lands for development of new International airport by applying the appropriate treatment to overcome the issues that meets cost and time. Globally the increasing demands of trading and servicing activities require the development of an International airport in major cities. The Mumbai is one of the biggest commercial destinations of our country also necessitates the development of another airport besides the existing airport in the region. From the past few decades, researches and studies show various ways of ground improvements for the airport area in coastal regions. This study shows the cost optimization of ground improvement work by adopting the end on dumping of locally available blasted rocks instead of ground improvement techniques. This study works on principle that stone is puncturing to the very soft to soft clay and at the same time clay are getting displaced thus, effective thickness of clay is getting reduced. The objectives of this study are to optimize the cost of ground improvement and reduce the residual settlement of airport land in coastal regions. Adopting of end on dumping methods is appropriate in view of cost and feasibility of site than the ground improvement techniques. The cost of end on dumping is Thirty-six percent less than the stone columns technique. It can be concluded that for future ground development projects filling of stones by the end of the dumping method can be considered as the appropriate solution concerning time and cost.

Keywords: Ground Improvement, end on dumping method, Bore logs data, stone columns. Navi Mumbai International Airport.
\end{abstract}

\section{INTRODUCTION}

Considering free connectivity, functioning suitability and bare minimum disturbances to population, ease of use of land, accessibility, and ease of use of physical \& social infrastructure Navi Mumbai site has been selected for the proposed Airport. Since the proposed airport is to be built on marshy land having zero or below zero ground elevation with respect to mean sea level,

Manuscript received on August 11, 2021.

Revised Manuscript received on August 18, 2021.

Manuscript published on August 30, 2021.

* Correspondence Author

M. P. Suryawanshi*, Post Graduate Student, Department of Civil Engineering, Pillai HOC College of Engineering and Technology, Rasayani, Dist.Raigad-410207, Maharashtra, India. Email: manojs18279@gmail.com

Raju Narwade, Associates Professor, Department of Civil Engineering Department, Pillai HOC College of Engineering and Technology, Rasayani, Dist.Raigad-410207, Maharashtra, India. Email: rnarwade@mes.ac.in

Karthik Nagrajan, Associates Professor, Department of Civil Engineering, Pillai HOC College of Engineering and Technology, Rasayani, Dist.Raigad-410207, Maharashtra, India. Email: knagarajan@mes.ac.in

(C) The Authors. Published by Blue Eyes Intelligence Engineering and Sciences Publication (BEIESP). This is an open access article under the CC BY-NC-ND license (http://creativecommons.org/licenses/by-nc-nd/4.0/) it is necessary to improve the ground stability by providing ground improvement measures according to site condition and soil investigations. Upon the soil investigations, ground improvement is to be done by filling of locally available blasted rocks by using the end on dumping method. Cost of end on dumping is tune-up to Rs.19575/Sqm while in a stone column it is about Rs.30883/Sqm for particular site area of Navi Mumbai International Airport which comprising soft clay up to 4.5 to 5-meter Fig.05 shows boreholes locations taking for detail soil investigation within the site area and Table No. 01 shows the test results obtained during soli investigation. As the clay is very soft to soft, the stones are puncturing to the very soft to soft clay and at the same time clay is getting displaced. Thus, the effective thickness of clay is getting reduced Fig.07 shows reduction in clay thickness and Table 02 shows the test results obtained after reclamation. Providing stone columns for shallow depth of very soft to soft clay is not advisable.

\section{OBJECTIVES}

Following are some of the other objectives that have been dealt with in the research work.

i. To improve the ground stability by providing ground improvement measures to ascertain the no

residual settlement of ground.

ii. To optimize the cost of ground improvement by using end on dumping of locally available material

i.e Blasted rock.

iii. Soil investigation and interpretation of test results for further studies and applications.

\section{LITERATURE REVIEW}

Masaki Kitazume (2015) was studied various ground improvements techniques like vertical drain, preloading, etc. used at Haneda/Tokyo Airport. At this airport the sub soil was found as very soft too soft in nature and having low shear strength. This airport is first and one of the major airport in the Japan having $300 \mathrm{~m}$ long runway which in operation. This airport is expanded frequently and now having three runways and two terminal buildings on manmade island. To cater the increasing air transportation fourth runway was constructed along south side of existing airfield in 2010.

Yang Yu, Zhu Wang and HongYue Sun(2020) were studied about the design of stone column .In this study it is mentioned that stone columns are broadly used to strengthen the soft clay foundation strata.

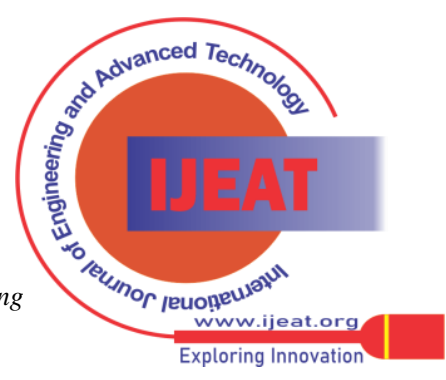


Design of stone column are based on the foundation strength. Cost is always important parameters for every designer and this consideration was kept in mind while designing of stone column. In this study it is also stated that, based on the settlement of stone column foundations, the failure probability of stone columns reinforced foundations are determining by using Monte Carlo simulation (MCS). The stranded standard deviation of failure probability is also used as measure of the design toughness due to uncertainty in coefficient of variation of the noise factors.

The study by Weizheng Liu, Zhiguo Shi, Junhui Zhang and Dingwen Zhang (2019) on one dimensional nonlinear consolidation behaviour of soft clay which is under the surcharge loading from long time. It is also mentioned in this study that existing logical solutions can give well results in respect of excess pore pressure than semi analytical studies which was verified against the field test and measurements. On the consolidation behaviour of soft soil, various studies were conducted to analyse the effect of permeability index, YSR and compression index. In this research it is also studied about the nonlinear compressibility, permeability and yielding due to structural degradation and their effect on consolidation of soft soils.

You Wang, Lin Li, Jingpei Li and Del'an Sun (2020) were studied about the grouting in soft soils. In this study the concept of saturation grouting is a generally used as technique to improve the condition of soft ground. By predict the saturation range of grout, it is very useful to know about the effect of grouting. This study is mainly about the jet grouting and rotary grouting for ground improvement. In this study theoretical analysis was conducted to check the effectiveness of grouting in ground improvement. By suing the Biotl's s theory and LaplaceFourier integral transform technique various studies were conducted to decide the saturation range of grouting.

Alonso, E., Gens, A. \& Lloret, (2020) -In this study assumption was taken in consideration that recompression is the one of best method for achieving the desirable ground improvement. By obtaining the distributions of displacement throughout the foundation depth by installing extensometers and sliding micrometre is very helpful to identify the mechanism of behaviour of controlling ground deformation the installation. Also by conducting the instrumented preload test, the reliable information was obtained for further actions. Upon the over consolidation state of soil, the magnitude of displacement was largely dependent. By applying the preload over a limited period primary consolidation settlement occurs very quickly but main design criteria are concerns about the secondary settlements. The field and laboratory tests are indicating clearly that over consolidation even in low amounts, considerable reduce the secondary compression rate. During the preload test the crucial information was achieved in this regards. It was also concluding in this study that application of preload surcharge larger that ultimate load is very effective in respect of controlling the magnitude of subsequent secondary settlements. Also the information collects during soil investigations and preload test providing base for the computing the settlement histories and ground deformation models. These models are being used for the final proposal of the precompressions treatment required for the various structures [8].

Ramil Nazir (2013) has studied about New Kuala Lumpur International Airport:In this study report, use of prefabricated vertical drain and preloading has proved that it is the one of economical ground improvement methods. This type of ground improvement was used in Airport-2 of New Kulal Lumpur. This airport was constructed on very soft clay. In view of existing ground nature surcharge preloading and prefabricated vertical drains were used in this airport construction. It was highlighted in this study that the all above techniques are based on the history of extent of settlement observed after filling. Also difference in settlement readings is predictable based on the certain constraints in soil parameters envisaged during soil investigations. Also this study worked on the compression between the theoretical calculations and observations taking during instrumentation. [5]

Almudena Da Casta (2015): Santander Airport, Spain: This site was reclaimed in sixties by using the soft material i.e from silty clay to clayey silt which is having low shear strength ranging from 10-20 kpa. In this study the ground improvement techniques like vertical drains and stone columns are found in line with observed values. Preliminary studies indicated that even for a very low embankment (1.5 m high), the delayed settlements could be of about $0.50 \mathrm{~m}$. This lead to the need for detailed geotechnical analyses including site exploration, ground improvement, and geotechnical monitoring during the construction. [6]

\section{Summary}

Above studies suggested about various ground improvement measures like preloading, prefabricated

vertical drains, and application of preload surcharge larger that ultimate load is very effective in

respect of controlling the magnitude of subsequent secondary settlements. All these ways of ground

improvement is quite expensive than end on dumping of locally available material like blasted rocks.

\section{PROBLEM STATEMENT}

A construction of new airport in any country by implementing the above mentioned ground improvement techniques rare. The methodologies mentioned in above reports was considered for the wide are i.e airport, unlike highway, road etc that consist the small strip area. Residual settlement in the ground is become a big challenge in geotechnical engineering to choose the appropriate treatment to overcome the issues that meets cost and time. The assumptions of the permanent load that would give an impaction the consolidating soil also became significant especially the live load from the aircraft that affect the pavement of the parking apron. This in return affects the estimation of both primary and secondary settlement.

The site consists of very thick soft marine clay overlaid by $4.5 \mathrm{~m}$ to $5 \mathrm{~m}$ thick of peat soil was treated by surcharge preloading technique by the end on dumping of locally available blasted rocks.

The reliability of the adopted ground treatment scheme was assessed by taking boreholes after filling,

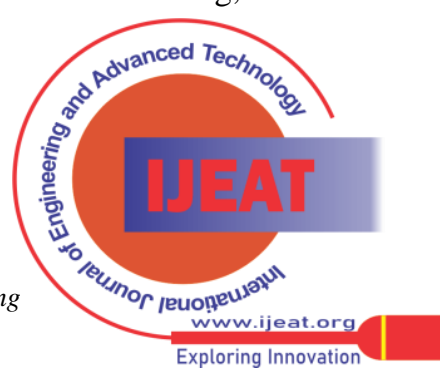


installing settlement instrumentations such as settlement plate, marker, piezometer, extensometer, and inclinometer. The argument rises as the treatment was not considered in removing the peat soil as some researchers claimed that surcharge preloading was not suitable for the ground to possess very thick peat soil. Hence, the prediction of residual settlement upon the ground improvement is of concern as the huge residual settlement will affect the pavement integrity and subsequently affect the airport operation. However, by applying a high surcharge, it was expected that blasted stones are puncturing to the very soft to soft clay and at the same time clay are getting displaced thus effective thickness of clay is getting reduced by some extent and primary settlement under the permanent load will be eliminated and the residual (secondary) settlement will be reduced Fig.07 shows how the clay gets reduced.

\section{STUDY AREA}

The study area for this the paper is Navi Mumbai International Airport area. Which is situated near the Panvel, Navi Mumbai along the panvel creek. Most of the area is having marine clay and marshy land. Also the existing Ulwe river is passed through the entire area of proposed airport which needs to divert. This is also big challenge to improve the ground condition for the airport. 1160 hectors of land is proposed for the airport. Since the proposed site is falling adjacent to Panvel creek and having the soft and marine clay about 4 to 5 meter depth, it is very necessary to improve the ground to considering the effect of Time and cost.

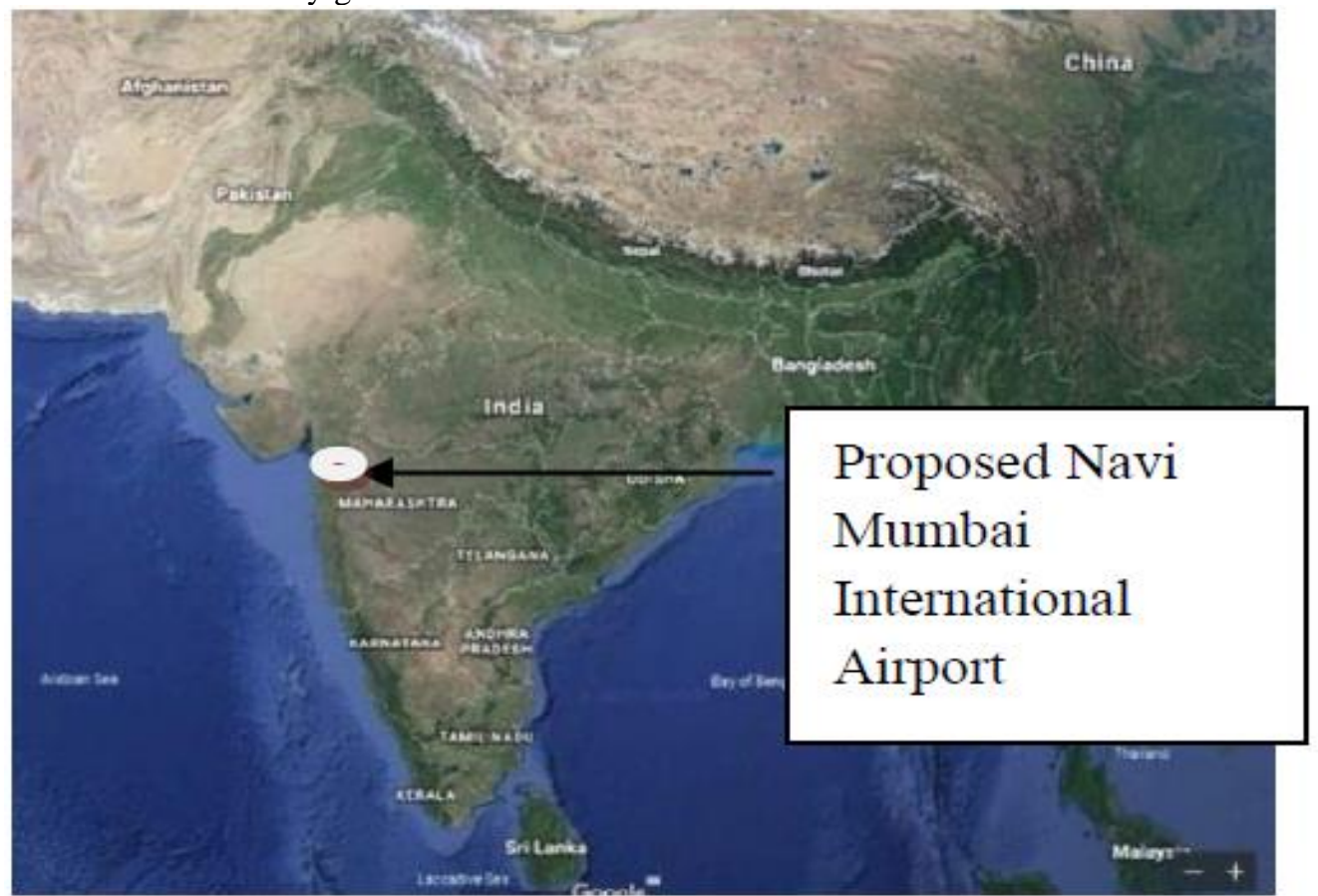

Fig. 1 Location of Navi Mumbai International Airport

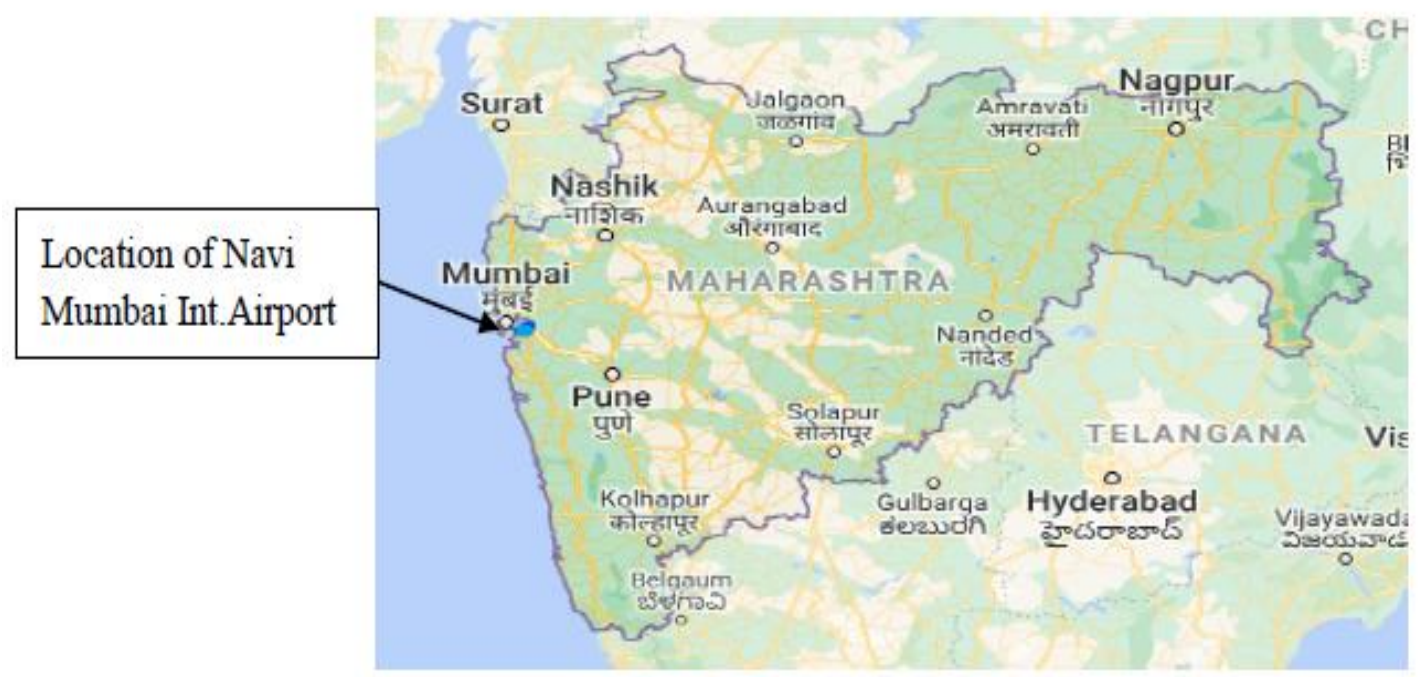

Fig.02 Location Map

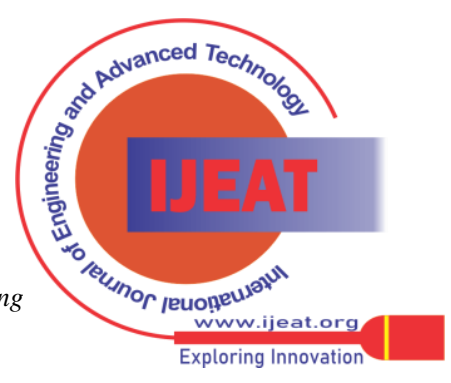



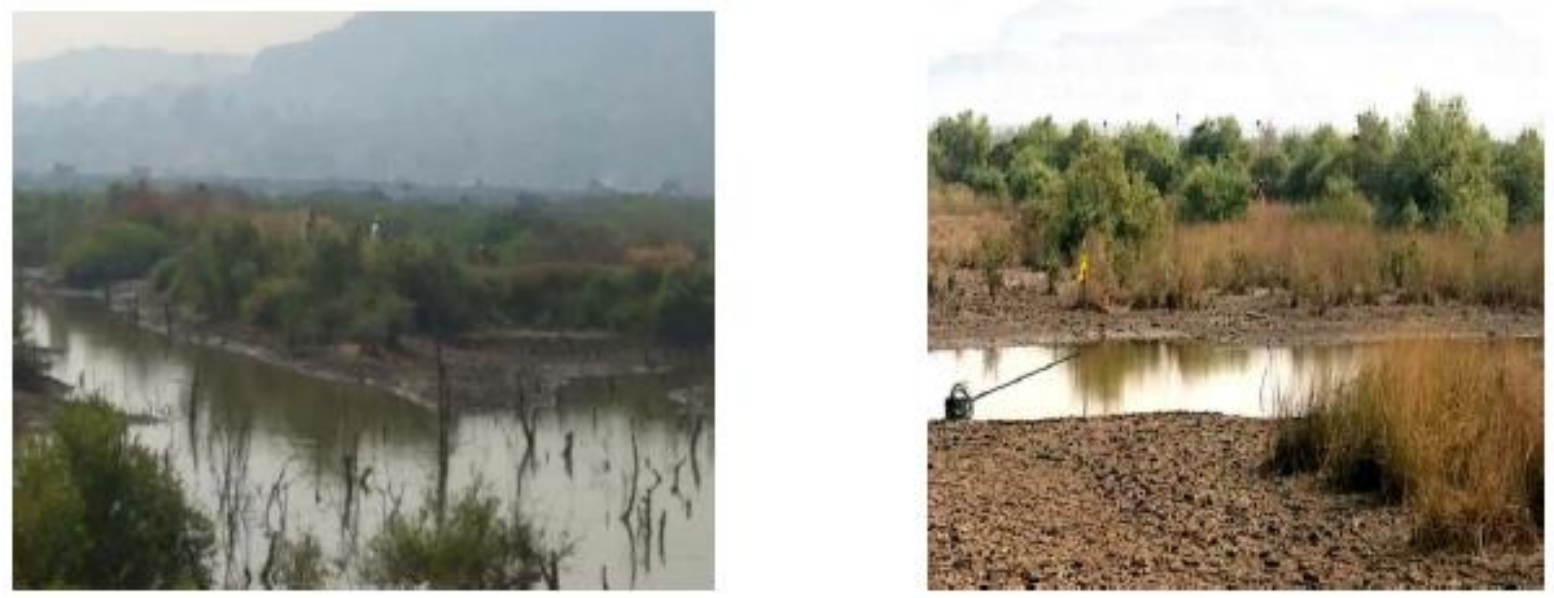

Fig.03 Site condition before reclamation

VI. METHODOLOGY

\section{Soil Investigations \& Data Collection}

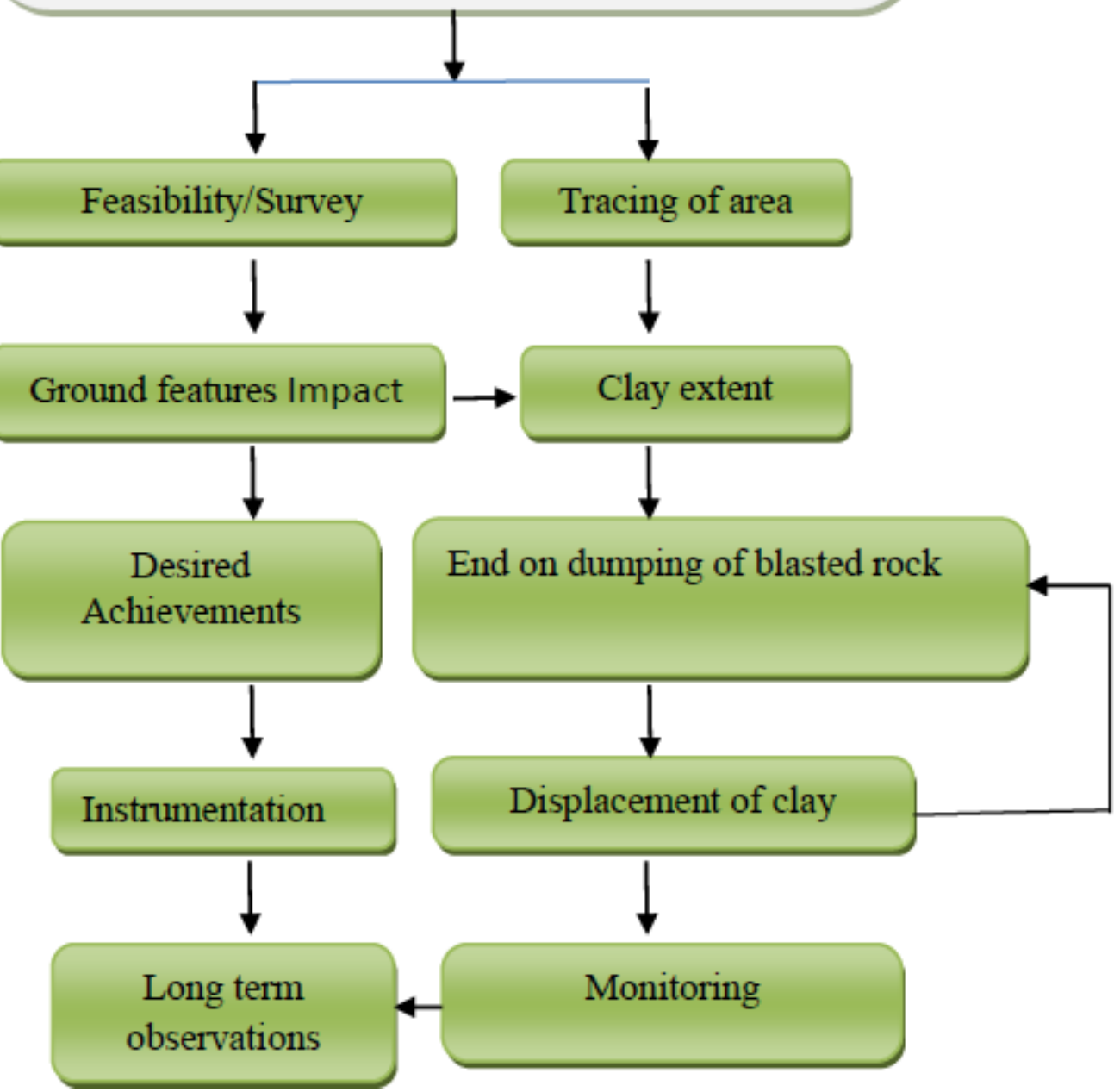

\section{A. DATA COLLECTION}

Since the site falling within coastal region and needs to special attention regarding the ground stability and strength. This airport is the Greenfield airport which is built near the Panvel creek. Various methods are being adopted for the ground improvement at earlier airports which was constructed along the creek sides i.e prefabricated vertical drain, stone columns etc.
To ascertain the ground strata, 41 boreholes are taken along the Northern side of Navi Mumbai International Airport. Fig 05 shows the location of boreholes and Table 01 shows the details test results obtained from soil investigations.

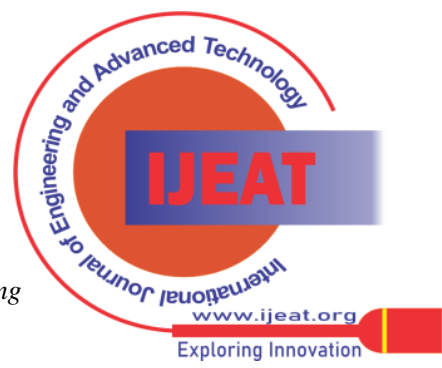




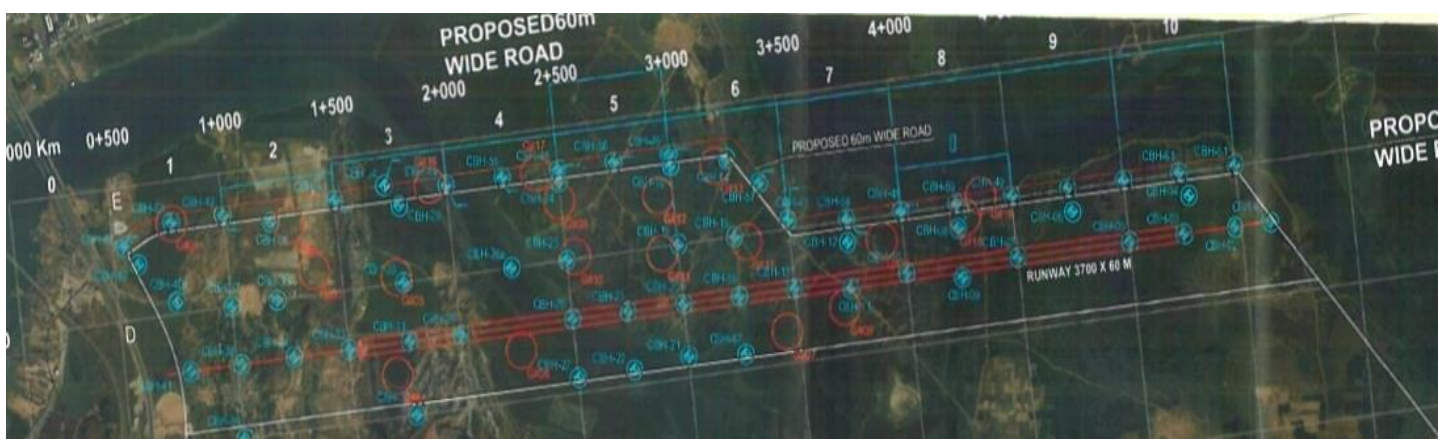

Figure 5: Location of boreholes taken for soil Investigation (Source CIDCO)

Table I: Borehole data (Source: CIDCO)

\begin{tabular}{|c|c|c|c|c|c|c|c|}
\hline \multirow{3}{*}{$\begin{array}{l}\text { Bore } \\
\text { Hole No }\end{array}$} & \multirow{2}{*}{$\begin{array}{l}\text { Thickness } \\
\text { of Clay }\end{array}$} & \multirow{2}{*}{$\begin{array}{l}\text { SPT 'N' } \\
\text { Values }\end{array}$} & \multicolumn{2}{|c|}{$\begin{array}{ll}\text { Undrained } & \text { Shear } \\
\text { Strength qu } & \\
\end{array}$} & \multirow{2}{*}{$\begin{array}{l}\text { Average } \\
\text { qu }\end{array}$} & \multicolumn{2}{|c|}{$\begin{array}{l}\text { Undrained } \\
\text { Cohesion Cu }\end{array}$} \\
\hline & & & VST-1 & VST-2 & & $\begin{array}{l}\text { From } \\
\text { VST }\end{array}$ & $\begin{array}{l}\text { From } \\
\text { Triaxial }\end{array}$ \\
\hline & $M$ & & $T / m^{2}$ & $T / m^{2}$ & $T / m^{2}$ & $T / m^{2}$ & $T / m^{2}$ \\
\hline CBH-1 & 4 & 3.4 & 3.75 & & 3.75 & 1.875 & 1.6 \\
\hline CBH-2 & 3.8 & 4 & 4.02 & & 4.02 & 2.01 & \\
\hline CBH-3 & 3,6 & 4 & 3.69 & & 3.69 & 1.645 & 1.5 \\
\hline CBH-4 & 3.6 & 3.4 & 3.03 & & 3.03 & 1.515 & \\
\hline CBH-5 & 3.2 & 3 & 3.03 & & 3.03 & 1.515 & \\
\hline CBH-6 & 3.2 & 4 & 3.75 & & 3.75 & 1.875 & \\
\hline CBH-7 & 4.1 & 3.4 & 2.69 & 3.23 & 3.06 & 1.53 & \\
\hline CBH-8 & 3.9 & 3.4 & 2.96 & 2.89 & 2.925 & 1.4625 & \\
\hline CBH-9 & 4.2 & 3.4 & 3.09 & 3.43 & 3.26 & 1.63 & \\
\hline CBH-10 & 4.5 & 3.4 & 3.09 & 3.56 & 3.325 & 1.6625 & \\
\hline CBH-11 & 4.1 & 4 & 3.75 & 3.43 & 3.59 & 1.795 & \\
\hline CBH-12 & 3.1 & 4 & 3.43 & & 3.43 & 1.715 & \\
\hline CBH-13 & 3 & 3 & 2.9 & & 2.9 & 1.45 & \\
\hline CBH-14 & 3.6 & 16 & & & & & \\
\hline CBH-15 & 3 & 3 & 3.03 & & 3.03 & 1.515 & \\
\hline CBH-16 & 2.4 & 3 & & & & & \\
\hline
\end{tabular}

Area classifies in different zones based on the thickness of Marine clay, locations, etc., and boreholes location based on the properties and extend of the soft clay stratum in these zones. As per the bore logs, the generalized subsurface stratum encountered as follows;

Stratum I: Very soft to soft Marine Clay Thickness of this stratum is varying between $1.5 \mathrm{~m}$. Standard penetration tests are conducted in this stratum and SPT ' $\mathrm{N}$ ' values are consistently observed between 2 to 4 with a few high values of 5 . This stratum has very low shear strength and a high potential for time-dependent settlements.

Stratum II: Medium Dense clay/Silt Sand-The thickness of the stratum varies between $0.3 \mathrm{~m}$ and $6.3 \mathrm{~m}$. Seventy-four SPT is conducted in this stratum.SPT ' $\mathrm{N}$ ' values vary between 15 and 30 with few high values observed between 36 to 40 . The range of SPT ' $\mathrm{N}$ ' values indicates the medium dense relative density of the cohesionless stratum. The sample tested from this stratum are classified as SM and SC.

Stratum III: Highly to Moderately Weathered Basalt-The boreholes were terminated in this stratum after penetrating over a depth ranging between $2.1 \mathrm{~m}$ and $10 \mathrm{~m}$. The core recovery and RQD are observed between nil and 90\% with the RQD value ranging between nil and 70\%.
The range of CR and RQD values indicates the rock mass. Stone columns represent the most known column type technique for improving the soil. They possess high compressive strength and stiffness relative to the soft soil. They do not only serve the function of reinforcement and drainage but they also increase the bearing capacity and reduce the settlement of soft ground. As per site condition apx. $3 \mathrm{~km}$ Ulwe hill is falling within the Airport site, blasted rock is easily available at a site without any extra lead. By filling of blasted rock with end on dumping method, soft to soft marine clay get displaced and thickness of clay reduced.

\section{RESULTS \& DISCUSSIONS}

As per the bore logs thickness of very soft to soft marine clay varies between $0.3 \mathrm{~m}$ to $5.7 \mathrm{~m}$ below EGL. The filling is done by the end of the dumping method. As the clay is very soft to soft, the stones are puncturing to the very soft to soft clay and at the same time clay is getting displaced. Thus, the effective thickness of clay is getting reduced.

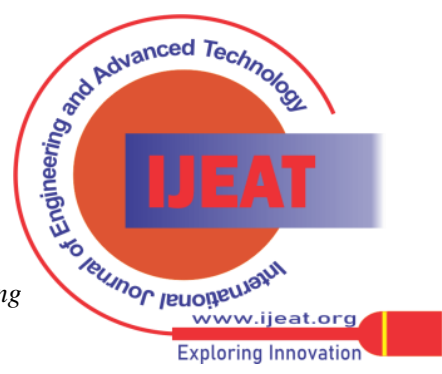




\section{Optimisation of Cost in Ground Improvement for Upcoming Navi Mumbai International Airport}

It is observed that displacement of clay is about $2 \mathrm{mtr}$ during end on dumping at the site. Therefore, providing stone columns in just $3.7 \mathrm{~m}$ thick very soft to soft clay is not advisable Fig. 07 shows how the rockfill material puncture the clay and reducing the clay thickness. For such a shallow depth of clay, a stone column is not requiring for a $3.0 \mathrm{~m}$ thick pad Indian standards 15284 defines that for shallow depth of clay, stone column is not feasible. To get the effect of control consolidation, it is required to lay a geotextile and proper drainage layer over the stone column treated ground, but it is not possible at the site due to the very soft consistency of clay. In absence of a proper drainage layer, properly inserted stone column of uniform diameter, the function of a stone column as uniform reinforcement to the ground and $3 \mathrm{D}$ consolidation is questionable. As the consistency of clay stratum is ranging from very soft to soft, the over breakage of stone will be high and it is difficult to control the quality of the stone column.

Due to the high breakage of material, the net spacing between the column will get reduce, which will affect the lateral bulging of stones and thus the safe bearing capacity of the treated ground. The stratum underlying the very soft to soft clay is medium dense sand which is a permeable stratum and it will provide a drainage face to overlaying very soft to soft clay. Similarly, the filling is a crushed stone which will also provide a drainage face. The remaining Thickness of a very soft to soft clay sandwich between two permeable layers and it will consolidate in two-way drainage and get consolidate under a pressure of $22 \mathrm{~T} / \mathrm{M} 2$ due to filling, which is huge consolidation pressure. Beneath the very soft to soft clay stratum, silty sand was encountered and having ' $\mathrm{N}$ ' value ranging from 13 to 26over the maximum thickness of $6.3 \mathrm{~m}$. Hence, there is no need to provide the stone column in this medium-dense sandy stratum. The sandy stratum is permeable and it will get compressed under a pressure of 21 T/M2.Actual Photographs showing the the extent of marine clay and Oozing of clay after filling;

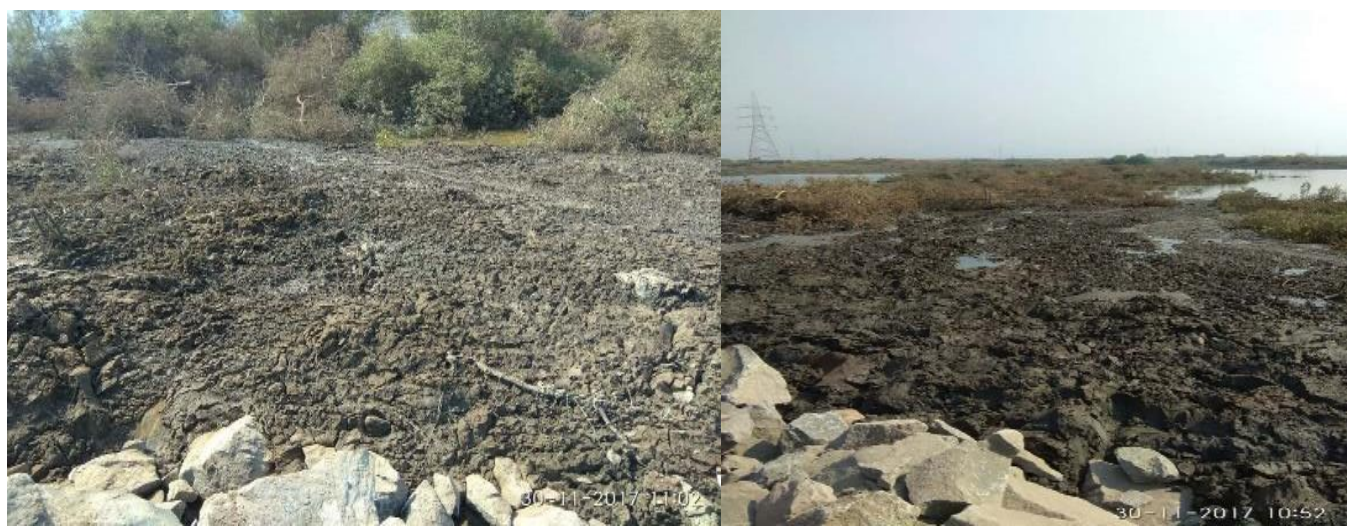

Fig.6: oozing/displacement of clay after end on dumping of blasted rocks (Source CIDCO)

\section{A. THE SOIL INVESTIGATION AFTER 1 YEAR OF FILLING OF ROCK FILL, SHOWS THE IMPROVEMENT OF SOIL CONDITION. THE TEST RESULT AS BELOW;}

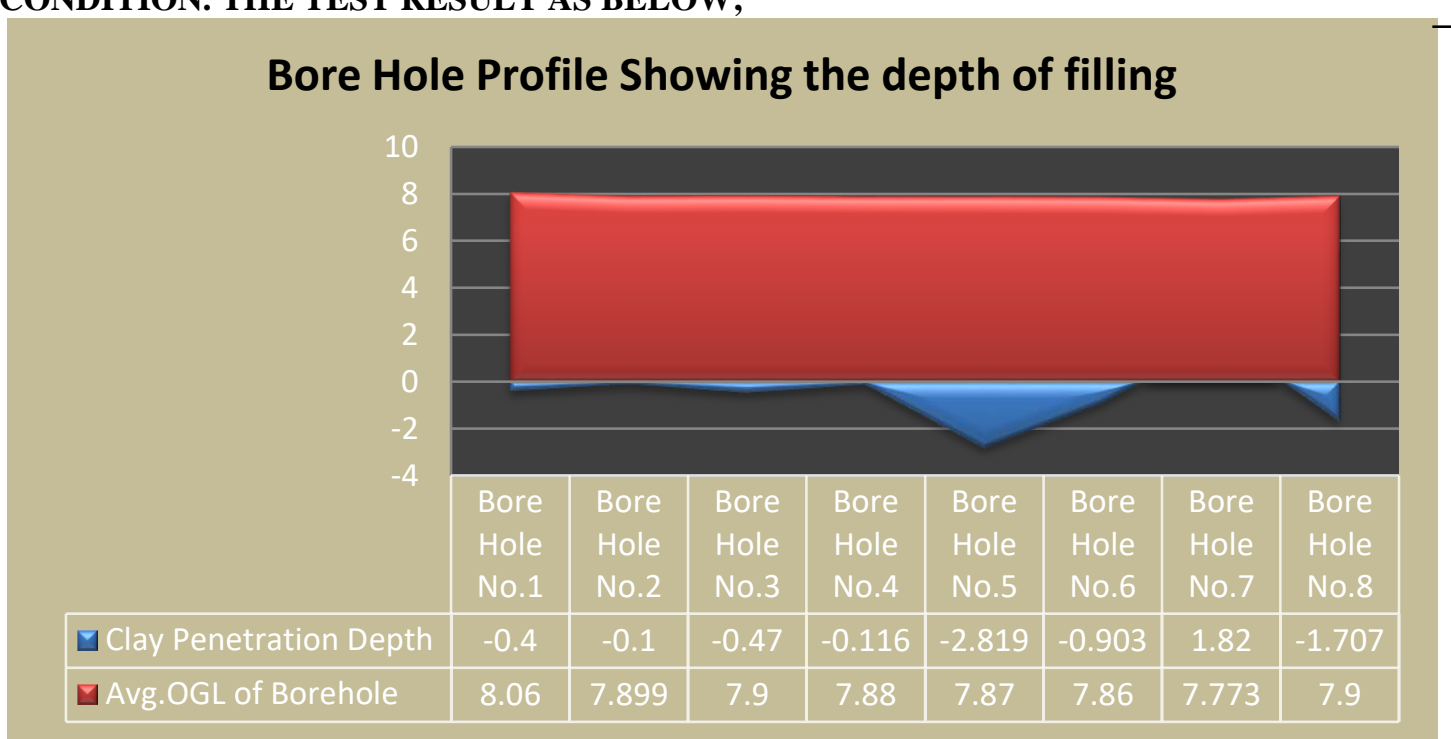

Fig. 07: Profile of Boreholes after filling (Source CIDCO)

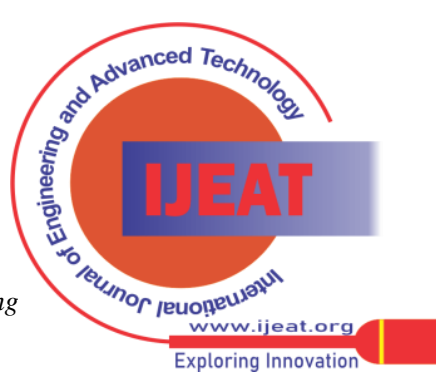


Table-No.02 Soil Investigation after End on dumping (Source: CIDCO)

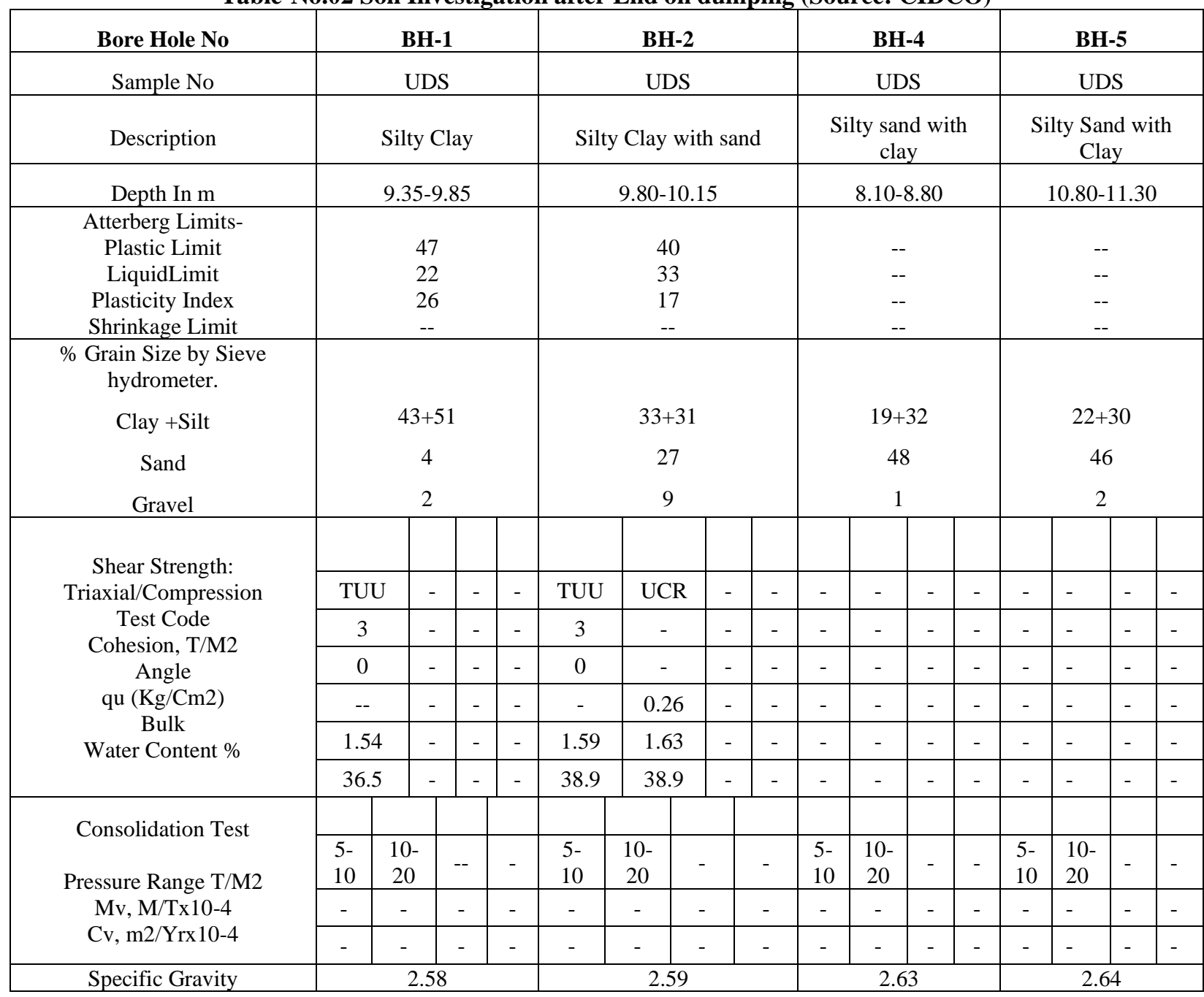

TUU: Unconsolidated Undrained DUD: Unconsolidated Drained Mv: Coefficient of Volume decrease

TCU: Consolidated Undrained $\quad$ DUU: Unconsolidated Undrained $\quad \mathrm{Cv}$ : Coefficient of Consolidation

TCD: Consolidated drained $\quad$ DCU: Consolidated Undrained

UCU: Undisturbed $\quad$ DCD: Consolidated Drained

UCR: Remoulded LV: Laboratory Vane

\section{CONCLUSION}

In the particular case of Navi Mumbai International Airport, where the depth of marine clay is significant and bearing low shear strength. To meet the requirement of the load-bearing capacity of the underlying soil, it is necessary to improve the ground condition by various modes, proposed stone column is about; Dia.- $900 \mathrm{~mm}$, Spacing $1.1 \mathrm{mtr} \mathrm{c} / \mathrm{c}$ triangular pattern \& area replacement of $64 \%$ area replacement. As per the IS, the 15284 (Part-I) area replacement ratio should be $20 \%$. In view of the above, it is concluded that the way of ground improvement by stone column is not appropriate concerning feasibility and financially.

An alternate methodology that is to be executed is the filling of rockfill material which is available from blasting at Ulwe hill, so no additional lead is required. Stone is puncturing to the very soft to soft clay and at the same time clay is getting displaced. Thus, the effective thickness of clay is getting reduced.

The Cost of rockfill is $36 \%$ less than the cost of the stone column.

\section{REFERENCES}

1. Masaki Kitazame (2015) "Ground Improvement in Haneda Tokyo International Airport”, icevirtullibrary.com, 165,(2),77-86. https://doi.org/10.1680/grim.10.00031

2. Yang Yu, Zhu Wang and HongYue Sun(2020) "Optimal design of stone columns reinforced soft clay foundation considering design robustness" techno-press, 22,305-318. http://dx.doi.org/10.12989/gae.2020.22.4.305

3. Weizheng Liu, Zhiguo Shi, Junhui Zhang and Dingwen Zhang (2019) " One-dimensional nonlinear consolidation behaviour of structured soft clay under time-dependent loading" techno-press 18,(3),

299-313 http://dx.doi.org/10.12989/gae.2019.18.3.299

4. You Wang, Lin Li, Jingpei Li and Del'an Sun (2020) "Jet-grouting in ground improvement and rotary grouting pile installation Theoretical analysis" techno-press 21,(3) 279-288 http://dx.doi.org/10.12989/gae.2020.21.3.279

5. Alonso, E., Gens, A. \& Lloret, A. (2000) "Precompression design for secondary settlement reduction" Geotechnique,

645-656 https://doi.org/10.1680/geot.2000.50.6.645

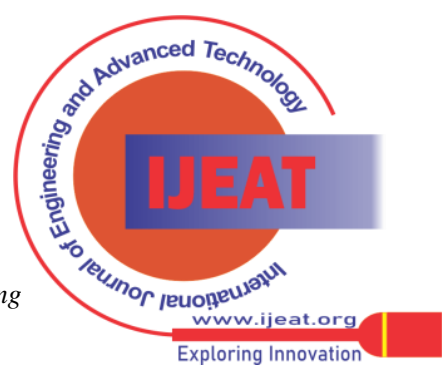


6. Ramil Nazir (2013) "Case study of ground Improvement of Kualalumpur International Airport" Conference: Foundation and Soft Ground Engineering Challenges in Mekong Delta, Thu Dau Mot University https://www.researchgate.net/publication/1259291855

7. Almundena Da Casta (2015) "Geotechnical aspects of airport extension on the soil of very low strength"

https://reaearchgate.net Conference: 16th European Conference on Soil Mechanics and Geotechnical

Engineering At: Edinburgh https://www.researchgate.net/publication/1259291855

8. Jay Ameratunga, Nagaratnam sivakugam, Braja M.Das ((2021), Soft Clay Engineering and Ground Improvement,CRC Press, London, UK

9. IS 15284 (Part-I):2003 Design And Construction for Ground Improvement Guidelines, Indian Standards, India

10. https://theconstructor.org/geotechnical/ground-improvement/,Various ground improvement and soil stabilization techniques used in construction works in world, www.theconstructor.org

11. CIDCO, City \& Industrial Development Corporation of Maharashtra.

\section{AUTHORS PROFILE}

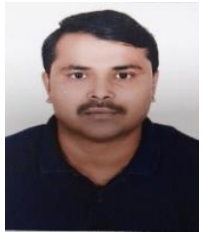

Mr.Manoj P. Suryawanshi, Post Graduate Student in Civil Engineering. Bachelor of Engineering degree in Civil Engineering from Kaviyitri Bahinabai Chaudhari North Maharashtra University Jalgaon in 2002. Pursing. Master`s Degree in Construction Engineering and management from Pillai HOC College of Engineering and Technology Rasayani, Dist.Panvel. Now Working in the Project of Prime Minister Awas Yojna, Mass Housing for Economical Weaker sections and Low income groups at Mumbai Region. Area of Interest: In Water Infra structures, Mass Housing Scheme

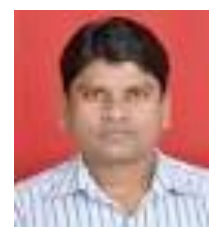

Mr. Raju Narwade, Associate Professor Department of Civil Engineering Pillai HOC College of Engineering and Technology, Rasayani. PhD (Pursuing) Mumbai University. Departmental advisor of Students' Chapter IEI (India) Areas of Interest are Structural Engineering, Hydrology, Remote Sensing and GIS

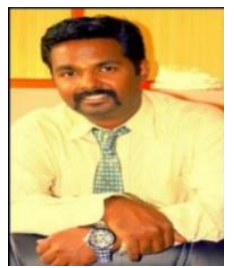

Mr. KarthikNagarajan, Associate Professor (PG \& UG Level), Civil Engineering Department, Pilla HOC College of Engineering \& Technology, Rasayani Pursing Ph.D. n Water Resources with application of Remote sensing and GIS. Network Coordinator of IIRS, ISRO Outreach Centre, PHCET. Areas of Interest are Remote Sensing, GIS, Water resources, Structural Engineering etc

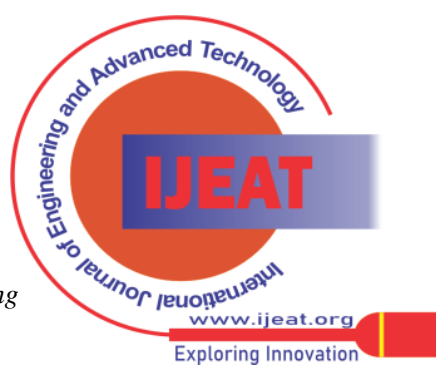

